\title{
Amyloid deposits in the knee joint at autopsy
}

\author{
CHR LADEFOGED
}

From the Institute of Pathology, Odense University Hospital, DK-5000 Odense C, Denmark

SUMMARY Joint capsule, meniscus, and cartilage from the patella and medial femoral condyle from 30 non-selected autopsies have been investigated for amyloid deposits with light and electron microscopy. Both right and left knee joints from 28 of the 30 autopsy specimens contained amyloid deposits $(93 \%)$. The amyloid characteristically showed green dichroism in ê polarised light after staining with alkaline Congo red. The ultrastructural features were also characteristic of amyloid. Amyloid in capsule tissue was found in a subsynovial location, as well $\infty_{\infty}$ as deeper in the capsule tissue, while in the cartilage amyloid was localised along the surface. The $ᄋ$ meniscus tissue, in particular, contained heavy deposits of amyloid-mainly along the inner $\rightarrow$ margin. Osteoarthritic changes, with fibrillation of the cartilage, were significantly related to amyloid deposition. No pathogenetic correlation between the osteoarthritic changes and amyloid deposition could be shown in the present investigation.

Key words: joint-amyloid, cartilage surface, synovial membrane.

Amyloid in joint tissue has been described earlier in connection with rheumatoid arthritis, ${ }^{1-3}$ myelomatosis, ${ }^{4-6}$ and with primary amyloidosis. ${ }^{7-9}$ Within the last 15 years the presence of amyloid has also been shown in systematic studies of surgical material removed from osteoarthritic hip joints, ${ }^{10-14}$ and in 1980 Ladefoged and Christensen found amyloid deposits in hip joint cartilage and capsule at autopsy. ${ }^{15}$ Mitrovic et al recently found amyloid in hip and knee joints. ${ }^{16}$

The present report describes the occurrence of amyloid in knee joint tissue from non-selected routine autopsies, and relates this to age, sex, and to other degenerative changes.

\section{Materials and methods}

The patient material was obtained from 30 randomly selected autopsies carried out at the Institute of Pathology, Odense University Hospital. No cases of generalised amyloidosis, rheumatoid arthritis, or myelomatosis were found. One patient had pulmonary tuberculosis and died from pulmonary congestion but without secondary amyloidosis in the parenchymal organs.

The average age for all the patients was 71.2 years (range 48-92); for the 12 women it was 73.5 years

Accepted for publication 16 January 1986.

Correspondence to Dr Chr Ladefoged. (range 48-92) and for the 18 men 69.9 years (range 48-89).

One block of tissue was taken from both the right $\frac{\mathrm{D}}{\mathrm{D}}$ and left knee, from the joint capsule with synovium, from the central part of the cartilage on the medial femoral condyle, and from the cartilage on the articular surface of the patella, as well as from the medial meniscus.

The tissue was fixed in $10 \%$ formalin for at least 48 hours, dehydrated, and embedded in paraffin, after which $6 \mu \mathrm{m}$ thick sections were cut and then stained with haematoxylin and eosin, van Gieson's connective tissue stain, and alkaline Congo red according to the method described by Puchtler et alo in $1962 .{ }^{19}$ Amyloid was considered present when the orange colour in the alkaline Congo red showed음 green dichroism in polarised light.

Selected amyloid positive blocks from 10 knees $\mathscr{\sigma}$ were stained with thioflavin- $T$ according to the $\tilde{O}$ method of Vasser and Culling. ${ }^{18}$

The same 10 blocks were used to check the sensitivity of the amyloid to pretreatment with $\mathrm{KMnO}_{4}$, as described by Wright et al in $1977 .{ }^{19} \frac{0}{\varnothing}$

The light microscopic findings were semiquanti- $\stackrel{\infty}{+}$ fied using $0=$ none; $+=$ slight, which had to be 0 searched for; $++=$ moderate, seen at once; and $\bar{P}$ $+++=$ heavy infiltration of the tissue.

Further, $1 \times 1 \times 1 \mathrm{~mm}$ tissue blocks were removed $\stackrel{\mathrm{Q}}{\mathrm{Q}}$ from capsule, cartilage, and meniscus from five of $\frac{}{O}$ the 60 knees ( 30 from the right side and 30 from the 
left); these were fixed in $2.5 \%$ glutaraldehyde in cacodylate buffer for electron microscopy. Pronounced amyloid degeneration had been found by means of light microscopic examination in two of the five cases. Tissue from these two autopsy specimens was then rinsed in $10 \%$ sucrose in cacodylate buffer and postfixed in $1 \%$ osmium tetroxide for two hours. It was then dehydrated in alcohol and propylene oxide, embedded in Epon, and cut for ultrastructural studies, which were carried out on a Philips EM 201 electron microscope.

\section{Results}

Both the right and left knee joints from 28 of the 30 autopsy specimens contained amyloid deposits $(93 \%)$. Two women, one of 48 years and one of 72 years, had no detectable amyloid in any of the investigated knee joint tissues, but for all the men and women no significant sex difference regarding the presence of amyloid deposition could be observed, neither was there any difference between the amount of amyloid on the right and left side.

The amyloid stained characteristically orange-red in alkaline Congo red and gave green dichroism in polarised light (Figs 1 and 2). Pretreatment with $\mathrm{KMnO}_{4}$ did not alter these characteristics.

Thioflavin-T stained sections showed a corresponding yellow-green fluorescence in ultraviolet light, using a BG12 exciter filter and a violet 3KV450 barrier filter.

Ultrastructurally, the characteristic collagen fibres were replaced in many places by a fibrillar material consisting of straight, crossing, nonbranching fibrils, having a diameter of between 8 and $25 \mathrm{~nm}$ (Fig. 3). Thirty of the 60 investigated knee joint capsules contained amyloid (Table 1). The amyloid was found as small focal deposits subsynovially and deep in the capsules, with no relation to the blood vessels. As may be seen from Table 1 there was significantly more amyloid present in the capsules from the older persons $(p<0 \cdot 01)$.

One half of the capsules contained various degrees of subsynovial hyalinisation and fibrosis. No correlation between these changes and amyloid could be shown.

The meniscus was the structure in the knee joint containing most amyloid. Fifty six of the 60 menisci were positive $(93 \%)$-four slight $(+), 34$ moderate $(++)$, and 18 severe $(+++)$. The amyloid was concentrated along the surface, particularly at the inner margin of the meniscus (Figs 1 and 2).

Fifty four joints were positive for amyloid deposits in respect of cartilage from the medial femoral condyle. In this tissue, as in the capsule, there was a

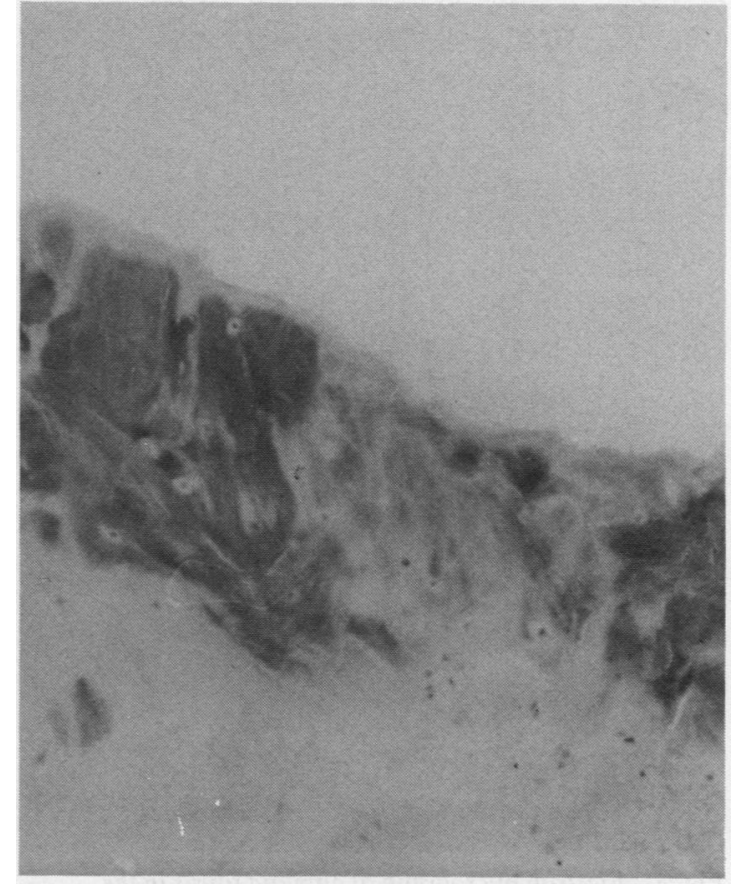

Fig. 1 Amyloid deposits in the inner rim of the meniscus. (Alkaline Congo red, $\times 100$ ).

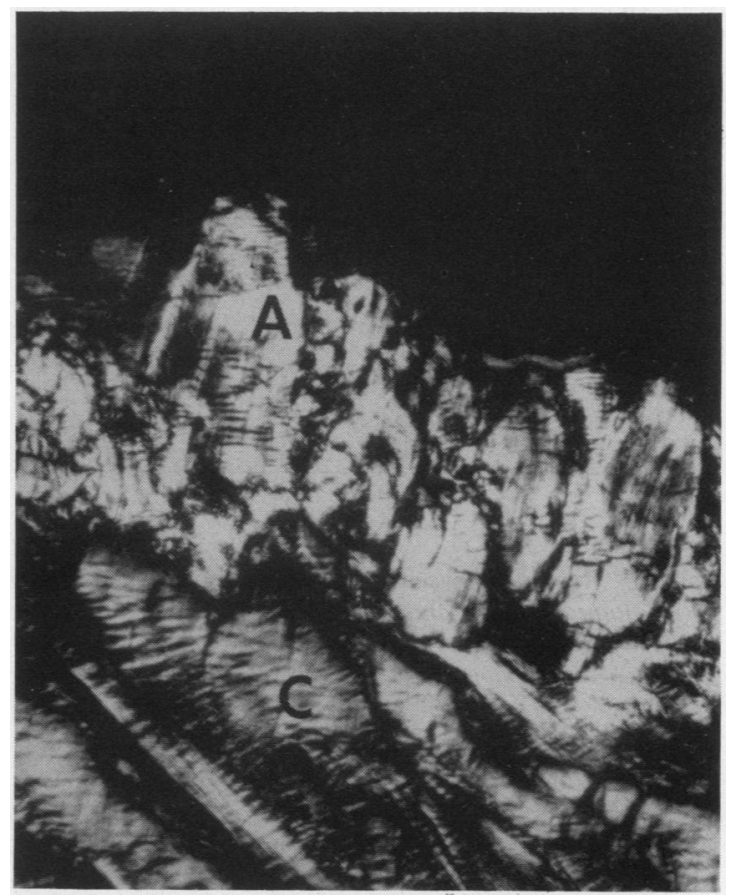

Fig. 2 Same as Fig. 1 in polarised light. Green birefringence from amyloid $(A)$ and grey birefringence from collagen $(C)$. 
Fig. 3 Electron micrograph of amyloid fibrils in the surface of articular cartilage from the knee joint $(A)$, collagen fibrils $(C)$, and joint surface at $(S)$. Autopsv material $(\times 26000)$.

Table 1 Relation between the degree of amyloid deposition in the joint capsule and age

\begin{tabular}{lccccc}
\hline Years & \multicolumn{2}{c}{ Amyloid } & & & Total \\
\cline { 2 - 4 } & 0 & + & ++ & +++ & \\
\hline $48-60$ & 7 & 3 & & & 10 \\
$61-70$ & 11 & 5 & & 16 \\
$71-80$ & 12 & 8 & 2 & & 22 \\
$81-92$ & & 7 & 5 & & 12 \\
Total & 30 & 23 & 7 & 0 & 60 \\
\hline
\end{tabular}

$\mathrm{p}<() \cdot 01$.

Table 2 Relation between the degree of amyloid deposition in the joint cartilage and age

\begin{tabular}{llrrll}
\hline Years & \multicolumn{2}{l}{ Amyloid } & \multicolumn{2}{c}{ Total } \\
\cline { 2 - 5 } & 0 & + & ++ & +++ & \\
\hline $48-60$ & 3 & 5 & 1 & 1 & 10 \\
$61-70$ & 1 & 8 & 7 & & 16 \\
$71-80$ & 2 & 7 & 12 & 1 & 22 \\
$81-92$ & & 1 & 6 & 5 & 12 \\
Total & 6 & 21 & 26 & 7 & 60 \\
\hline
\end{tabular}

$\mathrm{p}<0 \cdot 01$.

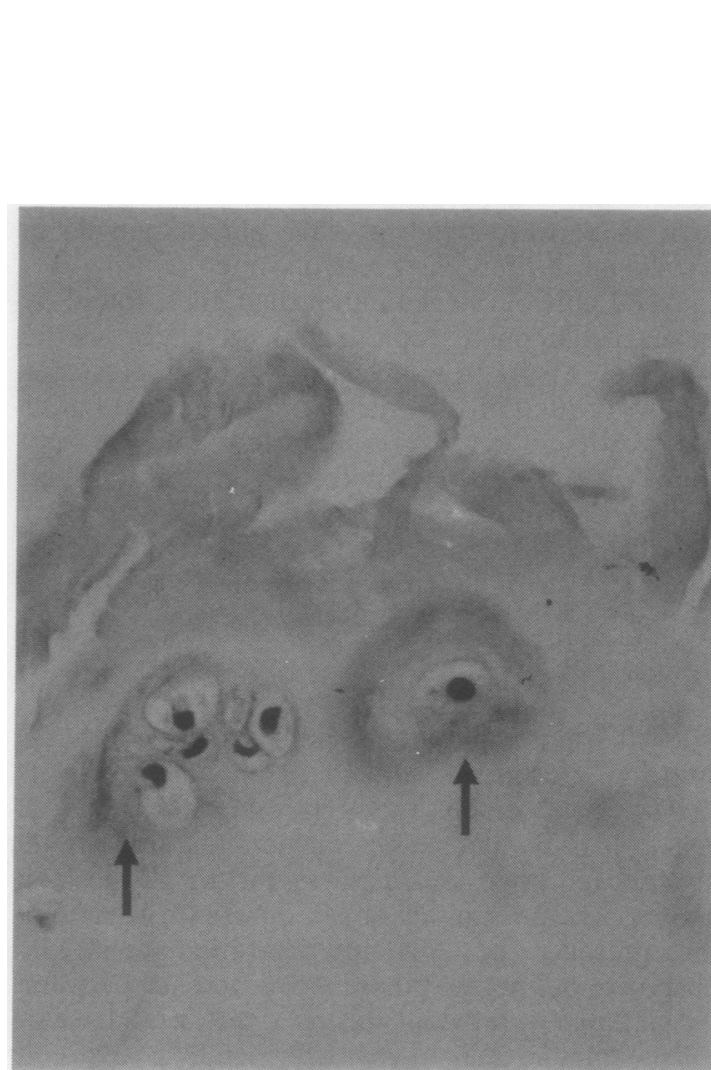

Fig. 4 Amyloid deposition in the surface of knee joint cartilage which is also attacked by severe fissuring.

Chondrocvtes surrounded by amvloid (arrows). (Alkaline

Congo red, $\times 400$ ).

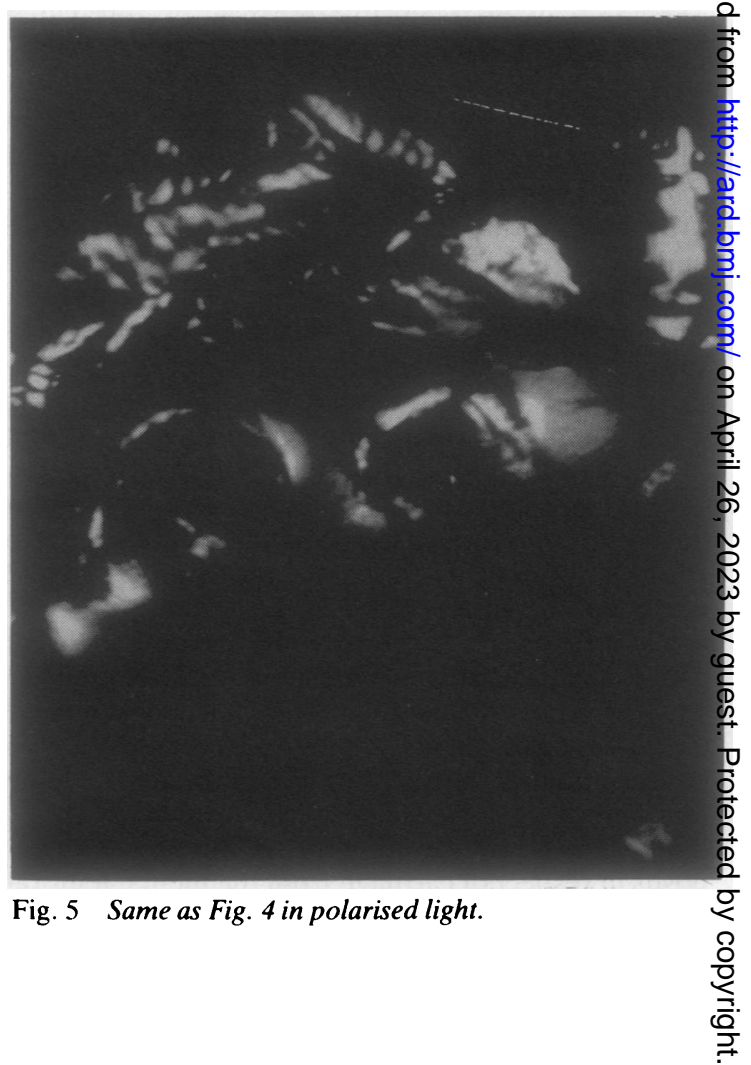


Table 3 Relation between the degree of amyloid deposition and degree of fibrillation of the joint cartilage surface

\begin{tabular}{llrrlr}
\hline Fibrillation & \multicolumn{2}{l}{ Amyloid } & \multicolumn{2}{c}{ Total } \\
\cline { 2 - 5 } & 0 & + & ++ & +++ \\
\hline 0 & 1 & 1 & 1 & 0 & 3 \\
+ & 4 & 18 & 10 & 2 & 34 \\
++ & 0 & 2 & 13 & 5 & 20 \\
+++ & 1 & 0 & 2 & 0 & 3 \\
Total & 6 & 21 & 26 & 7 & 60 \\
\hline
\end{tabular}

$\mathrm{p}<0 \cdot 001$.

significant age relationship, with more amyloid among the older patients (Table 2). The amyloid was deposited along the surface of the cartilage, often following fissures and ridges down into the tissue (Figs 4 and 5).

Various degrees of fibrillation of the cartilage were seen in nearly all the joints, and there was a strong correlation between the quantity of amyloid and the degree of fibrillation (Table 3 ).

Cartilage from the articular surface of the patella was the site of amyloid deposition in 52 of the 60 joints $(87 \%)$. As in cartilage from the condyle, amyloid was located along the surface, with a significant correlation between the degree of amyloid deposition and the degree of surface fibrillation $(\mathrm{p}<0.001)$.

Calcium pyrophosphate dihydrate deposits were found in joints from three patients, often with a close topographical correlation with amyloid.

\section{Discussion}

Wiernik, in a comprehensive review of the literature, found 16 probable cases of joint amyloid from 1873 to 1937 and a further 23 cases from 1938 to $1970 .^{20}$ In 1972 he reported a case of his own. Most of these 40 cases were associated with myelomatosis or generalised amyloidosis. The amyloid was found mainly in the large joints such as the shoulders, knees, and hips, but the elbows, wrists, and small joints of the hand also contained amyloid in several cases.

Severe clinical signs of joint disease with pain, stiffness, and swelling were often recorded. The average age of the patients was 52 years.

These findings differ in several respects from those in the systematic joint studies published during the last 15 years, including the present investigation. ${ }^{10} 1113-162122$ High incidences of joint amyloid have been found in these studies and may be characterised as follows: Firstly, the amyloid was only visible microscopically. Secondly, no association with myelomatosis, generalised primary or secondary amyloidosis was found. Thirdly, the average age of the patients was higher in the systematic studies and more amyloid was found in the older patients. Fourthly, the amyloid microdepositions did not correlate with clinical joint disease.

Ninety three per cent of the menisci in the present study contained amyloid, and to a greater extent than the other joint structures. In particular, the inner margin of each meniscus was infiltrated with amyloid. This tissue is interposed between the articular surfaces on the femoral and tibial condyles and is exposed to severe mechanical stress during movement. It can be compared, in this respect, with the calcified aortic and mitral heart valves, in which heavy amyloid degeneration also develops. ${ }^{23} 24$

In conclusion, microdeposition of amyloid in human knee joints from non-selected autopsies is very common. These deposits are heaviest in the older patients, as are osteoarthritic degenerative changes. $^{2526}$

From the results of the present investigation no conclusions can be reached, however, about the pathogenetic role of amyloid in the production of osteoarthritis. Further investigations on experimental animals will be necessary in order to unravel this problem.

\section{References}

1 Laine V, Vainio K, Ritama V V. Occurrence of amyloid in rheumatoid arthritis. Acta Rheumatol Scand 1955; 1: 43-6.

2 Linke R P, König G. RA und Amyloidose. Diagnostische Signifikanz eines löslichen synovialen Proteins mit immunologischer Kreuzreaktion mit dem Amyloid-Fibrillen-Protein A. Verh Dtsch Ges Rheumatol 1978; 5: 330-3.

3 Liard M E. Cywiner-Golenzer C H, Leclerc J P. Les microdepôts amyloides en rheumatologie. Arch Anat Cytol Pathol 1979; 27: 343-6.

4 Kruse P. Amyloid artropati. Ugeskr Laeger 1971; 133: 1777-9.

5 Kavanaugh J H. Multiple myeloma amyloid arthropathy and pathological fractures of the femur. J Bone Joint Surg 1978; 60A: $135-7$.

6 French B T. Amyloid arthropathy in myelomatosisintracytoplasmatic synovial deposits. Histopathology 1980; 4: 21-8.

7 Gamarski J. Netto M B. Manifestaqoes osteo-articulares na amyloidose primaria-apresentaqoe de caso. Arch Interamer Rheumatol 1959; 2: 651-63.

8 Bernhard G C. Hensley G T. Amyloid arthropathy. Arthritis Rheum 1969; 12: 444-53.

9 Bywaters E G L, Dorling J. Amyloid deposits in articular cartilage. Ann Rheum Dis 1970; 29: 294-306.

10 Christensen H E, Sørensen K H. Local amyloid formation of capsula fibrosa in arthrosis coxae. Acta Pathol Microbiol Immunol Scand $[A]$ 1972; 80 (suppl): 128-31.

$11 \mathrm{Mohr} W$. Amyloid deposits in the periarticular tissue. $Z$ Rheumatol 1976; 35: 412-7. 


\section{Ladefoged}

12 Ladefoged C. Amyloid in osteoarthritic hip joints. Acta Orthop Scand 1982: 53: 581-6.

13 Ladefoged C. Christensen H E. Sørensen K H. Amvloid in osteoarthritic hip joints. Acta Orthop Scand 1982: 53: 587-90.

14 Egan M W. Goldenberg D F. Segal D. Cohen A S. Unexpected amyloid and inflammatory synovial membranes in osteoarthritis. Arthritis Rheum 1980; 23: 668.

15 Ladefoged C, Christensen H E. Congophilic substance with green dichroism in hip joints in autopsy material. Acta Pathol Microbiol Immunol Scand $[A]$ 1980; 88: $55-8$.

16 Mitrovic D R. Stankovic A. Quintero M. Ryckewaert A Amyloid deposits in human knee and hip joints. Rheumatol Int 1985; 5: 83-9.

17 Puchtler H, Sweat F, Levine M. On the binding of Congo red by amyloid. J Histochem Cytochem. 1962: 10: 355-64.

18 Vassar P S, Culling C F A. Fluorescent stains with special reference to amyloid and connective tissue. Arch Pathol 1959; 68: $487-98$.
19 Wright J K. Calkins E, Humphrey R L. Potassium permanganate reaction in amyloidosis. Lab Invest 1977; 36: 274-81.

20 Wiernik P H. Amyloid joint disease. Medicine (Baltimore) 1972: 51: 465-79.

21 Goffin Y A. Thoua Y. Potvliege P R. Microdeposition of amyloid in the joints. Ann Rheum Dis 1981: 40: 27-33.

22 Ladefoged C. Amyloid deposits in human hip joints. Acta $\overline{\mathrm{G}}$ Pathol Microbiol Immunol Scand $[A]$ 1982: 90: 5-10.

23 Falk E. Ladefoged C. Christensen H E. Amyloid deposits in $\varrho$ calcified aortic valves. Acta Pathol Microbiol Immunol Scand [A] 1981: 89: 23-6.

24 Ladefoged C. Rohr N. Amyloid deposits in aortic and mitral $\vec{\circ}$ valves. Virchows Arch /Pathol Anat/ 1984: 404: 301-12.

25 Sokoloff L. The biology of degenerative joint disease. Chicago $\vec{\omega}$ and London: The University of Chicago Press, 1969: 6-10.

26 Stockwell R A. Changes in the acid glycosaminoglycan content of the matrix of ageing human articular cartilage. Ann Rheum Dis 1970: 29: $5(1) 9-15$. 